\title{
EN EL ORIGEN DE LA TOLERANCIA Y DE LA LIBERTAD DE CONCIENCIA: SERVET, CALVINO Y CASTELLIO
}

\author{
José MARTÍNEZ DE PISÓN CAVERO \\ CATEdRÁtico de Filosofía del DERECHO \\ UNIVERSIDAD DE LA RIOJA
}

Sumario: I. En el origen de la tolerancia y de la libertad de conciencia: Servet, Calvino y Castellio. II. Juan Calvino, el reformador teócrata. III. Miguel Servet, hereje. IV. Sebastián Castellio, infortunado defensor de la tolerancia y humanista. V. Bibliografía.

RESUMEN: La tolerancia y la libertad de conciencia, más allá de las controversias conceptuales que puedan generar, son dos conquistas de la lucha de la humanidad por el reconocimiento y positivación de los derechos fundamentales y las libertades individuales. De hecho, se encuentran en el origen histórico de la moderna concepción de los derechos y de la transformación de las categorías jurídico-políticas que tuvo lugar en Europa a partir del siglo XVI. En este artículo, se desarrolla la tesis de que el inicio de la reflexión filosófica acerca de la tolerancia y de la libertad de conciencia estuvo estrechamente ligado a la ruptura de la unidad religiosa producida por la Reforma y, en particular, al debate surgido en torno al tratamiento jurídico-religioso que merecían los herejes. En este sentido, el proceso, la condena y ejecución en la hoguera de Miguel Servet supuso un importante punto de inflexión. Puede afirmarse que, a partir de este momento, Sebastián Castellio alzará su voz contra Juan Calvino en favor de la tolerancia hacia los herejes iniciando ese lento, pero seguro proceso de conquista de los derechos fundamentales y de las libertades individuales.

PALABRAS ClAVE: tolerancia, libertad de conciencia, Reforma, herejes, Miguel Servet, Sebastián Castellio, Juan Calvino.

ABSTRACT: Tolerance and freedom of conscience, beyond the conceptual controversies that they can generate, are two conquests in the struggle of humankind for recognition and positivisation of fundamental rights and individual freedoms. In fact, they can be found in the historical origin of the modern conception of rights and of the transformation of the legal-political categories that took place in Europe from the I6th century onwards. This article develops the thesis that the start of philosophical reflection on tolerance and freedom of conscience was closely linked to the breakdown of religious unity produced by the Reform and, in particular, the debate that emerged regarding the legal-religious treatment that heretics deserved. In this sense, the trial, the sentencing and burning at the stake of Miguel Servet marked an important turning point. It can be said that, following that time, Sebastián Castellio would speak out against Juan Calvino in favour of tolerance towards heretics, thus starting the slow but steady process of achieving fundamental rights and individual freedoms.

KEYwORDS: tolerance, freedom of conscience, Reform, heretics, Miguel Servet, Sebastián Castellio, Juan Calvino. 


\section{En el origen de la tolerancia y de la libertad de conciencia: Servet, Calvino y Castellio}

La noche del 3i de octubre de I5I7, en la que Lutero clavó sus 95 tesis en la puerta de la catedral de Wittenberg, es una fecha emblemática para la historia de las religiones y, en particular, para el cristianismo puesto que, a partir de ese momento, se entiende que se inicia la Reforma protestante. La necesidad del proceso era evidente ya a finales del siglo XV y lo que hizo Lutero, realmente, fue poner de manifiesto la urgencia perentoria de llevar a cabo, en un sentido u otro, la reforma de la Iglesia católica ${ }^{\mathrm{I}}$. Pero, más allá de todo ello y de las interpretaciones que puedan realizarse, éste es un momento capital para la sociedad europea que trasciende lo meramente religioso para trasladarse a todos los aspectos de la vida social, cultural, política, económica de Europa. La «crisis de la conciencia europea»², tal y como la llamó Paul Hazard, se concretó con el tiempo en un proceso de transformación radical de la sociedad europea que la marcó para siempre y que tiene en este acto de rebeldía uno de sus hitos más destacados.

Las décadas posteriores al gesto de Lutero constituyen un período de incertidumbre en materia religiosa y de tensiones en el ámbito del reparto de poder en Europa. Guerras civiles y conflictos bélicos fueron, paradójicamente, los hechos históricos más señalados surgidos de la Reforma. Aún faltaría un tiempo hasta que volviesen a asentarse las fallas tectónicas removidas por el terremoto de la Reforma. Con todo, entre todo el fárrago de acontecimientos, debates, publicaciones, violencia y miseria, se produjeron algunas coincidencias que, aunque pueda parecer exagerado afirmar, tuvieron un papel importante en la conformación y conquista de las libertades individuales y los derechos fundamentales $\mathrm{y}$, en consecuencia, coadyuvaron, con el tiempo, a mejorar la sociedad europea.

Una de esas coincidencias, estelar en la historia europea, fue la «extraña amistad» que tuvieron tres protagonistas no menores de la Reforma protestante: Juan Calvino (I509I564), Miguel Servet (I5II-I553) y Sebastián Castellio (I5I5-I563). Calvino representa el severo y frío teólogo, capaz de llevar más allá de lo humanamente razonable su utopía religiosa a la realidad social y política en uno de los primeros actos de ingeniería social de la historia moderna; Servet, por el contrario, el cálido y alocado joven reformador, que propugna una «restitución» del cristianismo primigenio sin valorar las enormes fuerzas que la Reforma había desatado y que, en sus líneas capitales, no se orientaban en esa dirección; y Castellio, el humanista tranquilo y paciente que, a pesar de las adversidades y más allá de los debates teológicos, llama a las cosas por su nombre, y, como en el cuento del «rey desnudo», señala a Calvino y lo acusa de asesino al condenar a Servet a morir en la hoguera. No siempre ha sido suficientemente resaltado el extraño sortilegio que unió la vida de estas figuras eminentes del cristianismo y de la historia de la Reforma.

Y es que, en efecto, en esta conjunción de personalidades complejas, en un tiempo revuelto política y socialmente, se encuentra el origen del proceso de reivindicación de la tolerancia y de la libertad de conciencia y, por ende, de las libertades individuales y de los derechos fundamentales, y de las más importantes categorías jurídico-políticas de nuestras

${ }^{1}$ Una breve pero interesante introducción en CASTELLOTE, S., Reformas y Contrarreformas en la Europa del siglo XVI, Madrid, Akal, I997.

${ }^{2}$ Tal es el título del importante libro de Paul Hazard que, aunque centrado en el siglo XVII, esbozada la tesis del origen de la «crisis de la conciencia» en el inicio de la Reforma: HAZARD, P., La crisis de la conciencia europea, Madrid, Alianza Editorial, I988. 
sociedades occidentales. La obsesión de Calvino por el poder teocrático y la contumacia quijotesca de Servet deparó en uno de los procesos más miserables de la historia de la humanidad 3 . Y en ello podía haber terminado todo si no hubiese sido por la denuncia sincera y solitaria de Castellio y del eco que sus palabras tuvieron en las décadas posteriores hasta el punto de que todavía dos siglos más tarde Voltaire seguía denunciando la atrocidad cometida por los gobernantes de Ginebra. Sólo la oposición de Tomás Moro a las veleidades de Enrique VIII es comparable, en esa época, a los hechos aquí relatados. Esto es, la oposición al poder tiránico en defensa de las creencias personales y de la propia conciencia.

La Reforma protestante modificó la centralidad de muchos aspectos claves en la teología, en la política y en la sociedad proveniente de la Edad Media. Fue un proceso plagado de conflictos y luchas que acabaron por modificar el status quo medieval marcado por las tensiones entre Imperio y Papado, de manera que puede afirmarse que se encuentra en el origen del surgimiento de los nuevos estados nacionales y, en consecuencia, de la historia moderna europea. A pesar de los esfuerzos del Emperador por mantener la unidad de la conciencia cristiana, especialmente en un momento de potente auge del islam que presionaba por el oriente europeo, ésta se vería fragmentada y con ello la unidad política. De hecho, la disidencia religiosa fue un elemento más en el combate político que acabaría por alterar las bases de la sociedad europea.

Desde una perspectiva religiosa no hubo una sola Reforma, sino muchas Reformas, de la misma manera que la ruptura de la unidad cristiana no era la primera vez que sucedía en el seno de la Iglesia católica. Hubo debates teológicos y muy importantes desde los primeros tiempos del cristianismo. A su vez, estos se sucedieron cuando se produjo su institucionalización con la vinculación al Imperio Romano. Baste recordar la importancia del Concilio de Nicea (325) y el posterior de Constantinopla (38I), que ratifica la doctrina del anterior, para mostrar la existencia de la diferencia ideológica e interpretativa de los textos bíblicos y la cada vez mayor presión por sentar una únicas bases para toda la Iglesia. Ambos Concilios fueron convocados contra Arrio y el arrianismo que negaba la divinidad de Cristo y, en suma, el misterio de la Santísima Trinidad. Algo parecido sucederá en el desarrollo de la Reforma protestante cuando anabaptistas y otros, incluido el mismo Servet, reinventen estas tesis en aras de una vuelta al primigenio cristianismo.

Hubo varias Reformas, como también la Contrarreforma tuvo sus diferentes versiones. Para lo que nos interesa, conviene tener bien presente que, prácticamente, no hubo ciudad centroeuropea que no tuviera su reformador o reformadores y que sus tesis e interpretaciones de los pasajes bíblicos no siempre coincidían. Por supuesto, las grandes iglesias protestantes giran en torno a Lutero, Calvino y Zwinglio, inicialmente. Más tarde,

\footnotetext{
${ }^{3}$ Lo de «quijotesco», sin duda, es un tópico, pero en el caso de Servet fue utilizado por S. Zweig para hacer una brillante descripción del aragonés: «Se ha repetido hasta la saciedad que en cada español se oculta una vena quijotesca. En el caso de Miguel Servet, esta observación resulta, no obstante, perfecta y al mismo tiempo penosamente cierta. No sólo atendiendo a su retrato: este aragonés enjuto, pálido y con barba de perilla tiene un cierto parecido con el descarnado y magro héroe de la Mancha. Interiormente, está abrasado por la misma pasión sublime y grotesca de luchar por el absurdo y de arremeter con idealismo ciego de ira contra cualquier resistencia que encuentre en la realidad. Prescindiendo por completo de toda autocrítica, siempre descubriendo o afirmando algo, este caballero andante de la teología cabalga contra todos los baluartes y molinos de la época. Sólo le atrae la aventura, el absurdo, lo singular y peligroso, y con intenso placer bélico, irritado, anda a golpes con todos los demás iluminados, sin ligarse a ningún partido ni pertenecer a un clan, siempre solitario, al mismo tiempo imaginativo y fantástico, y por ello una figura excéntrica y única en su género». ZWEIG, S., Castellio contra Calvino. Conciencia contra violencia, trad. de B. Vías, Barcelona, Acantilado, 200I, pág. I05.
} 
surge la Iglesia anglicana. Y, poco a poco, diferentes sectas que acabaron por sufrir la persecución que las mismas iglesias reformadas criticaban.

Teológicamente, la doctrina protestante fue creándose a medida que los acontecimientos y las personalidades iban surgiendo y desarrollándose. En un principio, el acto de Lutero ante la catedral de Wittenberg fue un acto de protesta contra las indulgencias que se estaban concediendo, en particular, para la construcción de la basílica de San Pedro. El debate subsiguiente se centró ya en el cuestionamiento de la autoridad del Papa y en otros asuntos teológicos como el papel de la fe, el papel de los sacramentos, al Santísima Trinidad, etc. Fueron numerosas las discusiones, las disputas y los intentos por reconducir la protesta hacia la unidad, pero ello resultó imposible. Finalmente, Calvino, con sus Institución de la religión cristiana, dotó a los reformistas del armazón teológico sólido que necesitaban para llevar adelante la anhelada ruptura con Roma.

Aunque sea una simplificación, desde los primeros momentos, hay, al menos, tres tesis que unen a los reformadores: la justificación por la fe, la primacía de las Sagradas Escrituras sobre cualquier texto o interpretación y el odio al Papado (el Anticristo). Nada de esto era ajeno a la tradición escolástica, salvo el cuestionamiento de la autoridad del Papa que se fue afianzando desde los mencionados Concilios de Nicea y Constantinopla. Al margen de ello, esta actitud de reverencia a los textos y la importancia de la fe para la salvación derivaron en actitudes y en comportamientos que modificaron la religiosidad europea: se fomentó, gracias al auge de la imprenta, la lectura de la Biblia, que se tradujo a las lenguas nacionales, la libre interpretación, el diálogo directo con Dios, la protección del foro interno, etc.

Fueron, sin duda, muchas las cuestiones religiosas, políticas y sociales que se pusieron en el centro del debate a raíz de la Reforma. Una de ellas, y no menor, fue, finalmente, la del status de los herejes. No podía por menos que interesar a unos y a otros el debate sobre la situación de los disidentes en el seno de cada confesión. Con el paso del tiempo, fue una cuestión ineludible: primero, en la relación de los reformadores con la Iglesia católica; más tarde, en la de las nuevas sectas y las Iglesias protestantes institucionalizadas. Roma reaccionó, junto con los intentos de reconstruir la unidad religiosa con disputas o debates más o menos sinceros, con la excomunión, pero lo que suscita la polémica, es que los reformadores también utilizaron la violencia y la represión con las sectas y con sus disidentes. A partir de ahí, el proceso en favor de la libertad de conciencia era cuestión de tiempo.

Sin embargo, no siempre, en la historia de la Iglesia católica, la condena al hereje era sinónimo de represión y de violencia. Como ha sido bien estudiado, no existe en los textos bíblicos, ni hay justificación teológica para la represión y, menos todavía, la ejecución del hereje o del disidente. Con todo, esta práctica parece tener una fecha y un inicio bien claro, pero lo que es peor se institucionalizará en la existencia misma de la Inquisición y en la colusión entre poder espiritual y poder temporal que se producirá a partir de la conversión del emperador Constantino y del Concilio de Nicea ${ }^{4}$. Durante los siglos

${ }^{4}$ La fundamentación teológica y bíblica de la intolerancia no ha sido muy estudiada. Pero Ángel Alcalá ha sido muy claro en este extremo: «Se inició en la época constantiniana la doctrina de la intolerancia. Arrio mismo y los muchos obispos que le seguían, la mayoría de los asistentes al Concilio de Nicea, fueron excomulgados en él, que el oportunista Constantino personalmente presidió, porque éste decretó perseguir y desterrar a quienes no subscribieran el credo trinitario, que fue aprobado como dogma sin la necesaria libertad de los obispos firmantes. Pero el gran error táctico del concilio consistió en que para dirimir sus opiniones, que no tenían que 
posteriores, se asumirá como una estrategia necesaria para mantener la unidad de la cristiandad frente a las tendencias disgregadoras, los cismas, que los hubo y muchos durante la Edad Media.

El caso de Servet será, en este sentido, un punto de inflexión en el cuestionamiento de esta práctica, aunque no hay que perder de vista que fueron muchos, individual o colectivamente, los que se vieron privados de la libertad de conciencia reclamada al principio por los grandes reformadores. La condena de Servet, por Calvino y sus secuaces, a morir en la hoguera por sus creencias religiosas, distintas de las del reformador, el detonante de ese proceso de redefinición del papel del hereje -del disidente ideológico- y, en suma, de la reivindicación de la tolerancia y de la libertad de conciencia.

Como ya se ha escrito: «(...) el holocausto de Servet, además de su doctrina en contra de la intolerancia y a favor de la libertad de conciencia, fue el punto de partida del movimiento que, desarrollado por Castellio, y pasando sin solución de continuidad por los socinianos desterrados a Amsterdam, Spinoza, Locke y otros, desembocó en el reconocimiento de esa libertad en la Constitución del naciente Estados Unidos y, por su influjo y prestigio, reconocida como derecho natural en todas las constituciones democráticas. Para Calvino, como para la Iglesia de la Inquisición, era una novedad punible, cuando era la más antigua y auténtica tradición» ${ }^{5}$.

\section{Juan Calvino, el reformador teócrata}

La figura de Juan Calvino no pasa desapercibida ni para la historia de las religiones ni para la historia de las ideas, ni para la filosofía política. Lo cierto es que, a la vista de su vida, su obra y la práctica teológica-política, es difícil tener una visión imparcial y objetiva del reformador y del «gobernante» de una ciudad tan emblemática como Ginebra. Tal fue su dedicación al movimiento religioso que apadrinó y al proyecto político de una Ginebra ordenada de acuerdo a los nuevos dogmas surgidos de su visión reformadora del cristianismo. Desde luego, no cabe negarle pasión, siendo un hombre poco apasionado, ni tesón en el empeño de consolidar su lectura de la Reforma y de organizar el espacio público y la vida de sus feligreses de acuerdo a sus creencias básicas.

En la literatura sobre Calvino se puede encontrar desde las más ingenuas hagiografías hasta irónicos escritos que buscan desmitificar al ídolo. Paradójicamente, Calvino nunca fue partidario de la adulación, ni de mitificar su figura y su papel en la Reforma y en el gobierno de Ginebra; no le gustaba el oropel, el lujo, el protocolo pomposo, ni el espectáculo ni su exposición pública. Esta humildad deseada se mostraba en su ropa y vestimenta, en sus costumbres, en su rechazo a los retratos o al autobombo ${ }^{6}$. De hecho, entre otras cosas, no será hasta después de su muerte cuando uno de sus más íntimos

ver demasiado con la doctrina evangélica, pues eran de interpretación meramente teológica, las dos facciones (la trinitaria y la unitaria) acudieran a cobijarse bajo el poder imperial. Fue uno de los precedentes más perniciosos en toda la historia del cristianismo». Vid. AlCALÁ, A., «La sinrazón de la intolerancia en Tomás de Aquino y Juan Calvino: su rechazo por Miguel Servet, origen de la libertad de conciencia», en Escudero, J. A. (coord.), Intolerancia e Inquisición, Madrid, Sociedad Estatal de Conmemoraciones Culturales, 2006, pág. 86.

5 AlCAlÁ, A., «La sinrazón de la intolerancia en Tomás de Aquino y Juan Calvino: su rechazo por Miguel Servet, origen de la libertad de conciencia», cit., pág. 99.

${ }^{6}$ Crouzet ha llamado a esta actitud consciente de Calvino «voluntad de anonimato» coherente con su lógica creencia teocéntrica en el que Dios lo domina todo, su vida, sus emociones, su trabajo, su tiempo, etc. 
colaboradores, Theodor de Beza, escribirá una de las biografías más importantes sobre su personalidad.

Juan Calvino nació el año I509, en Noyon, ciudad situada en la Francia septentrional. La situación profesional de su padre le permitió acceder a una formación superior. Su padre trabajaba en el obispado de la ciudad y no carecía de una posición acomodada. Lo cierto es que su hijo Juan, gracias a la posición social, pudo estudiar humanidades, latín y retórica y continuar sus estudios, en este caso en Derecho, en la Universidad de Orléans, completando su formación en Bourges y en el Colegio Real de París. Su formación como jurista será muy relevante en la determinación del papel de Calvino en la Reforma protestante y, especialmente, en el gobierno de la ciudad de Ginebra. Sin ella, creo, es difícil entender muchas de sus actitudes y propuestas.

Se ha escrito y discutido mucho sobre la supuesta «iluminación» o «conversión» de Calvino y su aceptación del movimiento protestante. Lo cierto es que su primera acción conocida y relevante tuvo lugar en París. El rector de la Universidad de París, Nicolás Cop, sorprendió a todos con un discurso de apertura de curso, el I de noviembre de I533, en el que asumía alguna de las tesis más importantes de los protestantes, como, por ejemplo, la justificación por la fe. La opinión más extendida, aunque también muy discutida, fue que Calvino estaba detrás de las ideas centrales del discurso y de la aceptación, por lo tanto, de la Reforma protestante por parte de Cop C $^{7}$ Se originó un revuelo enorme. En particular, la reacción airada y violenta del rey Francisco I que prohibió estas creencias, su propagación y llegó a condenar a muerte a varios herejes. Por cierto que, por esa época, estaba también en París y en su Universidad otro joven llamado Miguel Servet con el que coincidiría también Calvino. Más allá de cualquier especulación, la realidad es que este último tuvo que huir de París e iniciar así un periplo por Centroeuropa que le acabaría llevando a Ginebra.

En efecto, su marcha de París acabó por conducir a Calvino a la ciudad de Estrasburgo, en la que la Reforma estaba liderada por Martin Bucero. Estando en esta ciudad, conoció a Guillermo Farel, hombre rudo y práctico, que puso a Calvino en la tesitura de dejar de ser un mero teórico para pasar a la acción liderando la Reforma en Ginebra o quedarse en un inoperante teólogo. La decisión de Calvino, que se resistió hasta el final, no fue fácil. Al final, decidió implicarse en el proyecto de Farel y, con ello, dio un nuevo giro a la reforma protestante ${ }^{8}$.

La entrada de Calvino y sus secuaces en Ginebra no fue sencilla al principio. El teólogo reformista nunca quiso un puesto público con poder real sobre el gobierno de la ciudad. Su posición debía ser únicamente de orientador de la comunidad en la nueva religión y sólo, desde ahí, desde su puesto de pastor del rebaño de los creyentes, dictaba cuál debía ser el comportamiento de sus ovejas y, por ende, de sus gobernantes. A pesar de no ocupar ningún puesto público relevante en ningún momento de su presencia en Ginebra, sin embargo, su poder fue inmenso. Su capacidad oratoria, su potestad para interpretar la

\footnotetext{
${ }^{7}$ Sobre el influjo o no de Calvino sobre el discurso del rector Cop, puede verse CrouzET, D., Calvino, trad. de $\mathrm{M}^{a}$ T. Garín, Madrid, Editorial Complutense, 200I, págs. 73 y ss. Para este especialista no está tan clara la supuesta paternidad de Calvino en el texto de dicho discurso.

${ }^{8}$ Farel conminó a Calvino a dar el paso con unas palabras contundentes: «Te escudas en tus estudios, pero, en nombre del Dios Todopoderoso, te anuncia que la maldición de Dios caerá sobre ti si niegas tu ayuda a la obra del Señor y te buscas más a ti mismo que a Jesucristo» ZwEIG, S., Castellio contra Calvino. Conciencia contra violencia, cit., pág. 3I.
} 
Biblia como lector de las Sagradas Escrituras -esto es, intérprete supremo del texto para el Consejo y la ciudad ginebrina- y, a partir de ahí, decidir lo que se debe o no hacer es un ejemplo de cómo gobernar una comunidad sin detentar ningún cargo público. A su poder simbólico se unía su facultad para excomulgar a quien no cumpliese con sus dictados, lo cual quería decir la expulsión de la ciudad, y, además, un aguerrido grupo de fieles que, al mando de Farel, conminaba al desobediente a cumplir con la voluntad de su líder. Con esta estrategia, poco a poco fue haciéndose dueño de toda la ciudad. No debe extrañar, pues, que para S. Zweig este tipo de estrategia sea un antecedente de los métodos aplicados por el nazismo para acceder y consolidar su poder y la tiranía política?

Pero, como adelanté, la presencia de Calvino en Ginebra no fue, desde luego, fácil. Sobre todo, al principio. Farrel convenció al teólogo en ${ }_{53} 6$ para que acudiera a Ginebra para continuar la obra reformadora. Tras la aclamación en la plaza de la ciudad por parte de los ciudadanos, Calvino se puso a reorganizar no sólo la actividad religiosa, sino también la vida de la comunidad. Para ello, llevo al Consejo de la ciudad la aprobación de un catecismo básico -su Confesión de Fe, con 2I artículos- que debía regular el comportamiento de los ciudadanos y al año siguiente, en I537, otro documento con varias exigencias para el gobierno de la comunidad y de la ciudad sobre el matrimonio, la catequesis y sobre la participación del pueblo en algunos ritos religiosos. En él se establecía el mecanismo básico de su futuro poder teocrático: la excomunión. Aquel que fuera excomulgado por no cumplir con los preceptos de Calvino no recibiría la comunión y quedaba marcado de una forma radical e indeleble.

Se llegó a tal punto porque, como puede colegirse de lo anterior, el lector de las Sagradas Escrituras no sólo estableció las reglas básicas de la interpretación del texto bíblico, sino que impuso una importante reforma de las costumbres en una ciudad, hasta entonces, liberal, abierta y festiva. Se prohibieron los bailes, la bebida y las reuniones públicas; se corrigieron las modas en el vestir y en la comida, así como las reglas de la vida privada, además de imponer el recogimiento y la lectura de la Biblia. No es de extrañar que la excomunión -es decir, que Calvino señalara a un individuo y a su familia por incumplimiento de sus puritanas reglas-, supusiera el ostracismo social. Automáticamente, se le cerraban todas las puertas de trabajo, del comercio y de las relaciones sociales. A la postre, implicaba su expulsión de la ciudad. Muchos ciudadanos de Ginebra optaron por el destierro ante tal estigma y ante la obcecación de una parte de sus conciudadanos.

En un primer momento, la imposición de estas reglas y, por tanto, del poder teocrático encontró algunas resistencias. Los pro-hombres y las familias importantes de la ciudad, cansados de sus prohibiciones poco acordes con las tradiciones de la ciudad, acabaron por destituir a Calvino de su puesto de lector de las Sagradas Escrituras. Era el día 25 de abril de 1538. Calvino, Farel y sus secuaces tuvieron que huir de la ciudad. Tras pasar por Basilea, el reformador pidió asilo a su amigo Bucero en Estrasburgo donde se dedicó al estudio y a mejorar su obra más importante. En esta ciudad, estuvo tres años hasta que cambiaron las tornas en Ginebra. En efecto, durante este periodo de tiempo, la correlación de fuerzas en la ciudad fue cambiando paulatinamente añadiendo a eso el que el sucesor de Calvino como lector no fue del agrado de los ciudadanos ginebrinos. El resultado fue que, al cabo del tiempo, muchos añoraron la capacidad, la sugestión y el poder de Calvino como

${ }^{9}$ Ibídem, págs. 69 y ss. 
orientador de la vida religiosa y, a la postre, política de la ciudad. El reformador fue invitado a volver de nuevo a Ginebra y a ocupar su anterior puesto. La decisión no fue fácil para Calvino quien tardó diez meses en asumir lo que, inicialmente, interpretó como una cruz que debería acarrear hasta su muerte. Regresó a Ginebra el i3 de septiembre de I54I instaurando su poder teocrático, esta vez, sin oposición alguna. No saldría de esa ciudad hasta su muerte el 27 de mayo de 1564.

El año I536, el de la primera entrada en Ginebra, es un hito importante en la vida de Calvino no sólo porque inicia el primer periodo del gobierno calvinista en Ginebra. Ese mismo año, Calvino publicó su obra magna: Institución de la Religión Cristiana. Su autor ya era conocido por algún otro escrito como un comentario sobre Séneca (I532), realizado todavía en París y que le valió un cierto reconocimiento como pensador. Y, de hecho, su obra, a lo largo de toda la vida, es muy numerosa.

No cabe duda que la Institución de Calvino es una obra que asienta el movimiento protestante, que le da solidez y un contenido más claro que el que aparece en los primeros reformadores, Lutero o Zwinglio. Le da capacidad organizativa y, por tanto, le habilitaba para garantizar su supervivencia en el tiempo, como así fue. Como dice el título, su objeto es teológico, pero, además, presenta una forma institucional, organizativa, para la nueva religión y sus seguidores. De ahí que Calvino y su Institución hayan sido la persona, el pensamiento y el instrumento de referencias y de consolidación del movimiento reformista. Nada más ilustrativo que la siguiente idea de Zweig sobre la obra magna de Calvino: «Esta Institutio es uno de los diez o veinte libros del mundo de los que, sin caer en la exageración, se puede decir que han cambiado decisivamente los acontecimientos en la Historia y la faz de Europa. La obra más importante de la Reforma, después de la traducción de la Biblia de Lutero, gracias a su lógico rigor y a su tenacidad constructiva, ejerció desde el primer momento una influencia decisiva sobre sus contemporáneos. Un movimiento espiritual necesita siempre de un hombre genial que lo inicie y de otro que lo lleve a término. Lutero, el inspirador, puso la Reforma en marcha. Calvino, el organizador, la detuvo antes de que se deshiciera en mil sectas» ${ }^{\mathrm{O}}$.

\section{Miguel Servet, hereje}

El gesto de Lutero ante la puerta de la catedral de Wittenberg a medio y largo plazo transformó la conciencia europea. Su deseo de reforma de la Iglesia se propagó con relativa facilidad por las grandes ciudades europeas y, pese a los intentos del Papa y sus obispos y del Emperador, las nuevas ideas fecundaron en muchas de las mentes más desarrolladas de la época dando lugar a una auténtica revolución ideológica. El principio básico de la lectura y libre interpretación de las Sagradas Escrituras se extendió ampliamente dando lugar a numerosas visiones de las diferentes cuestiones escolásticas de manera que, después de los grandes movimientos reformistas, surgieron diversas doctrinas religiosas y, a la postre, una multitud de sectas del estilo de los anabaptistas, socinianos, etc.

Un caso paradigmático de lectura libre y original de las Sagradas Escrituras será el de Miguel Servet. Las consecuencias de esta originalidad fueron trágicas para el desarrollo y el final de su vida, pues murió en la hoguera condenado por Calvino y los suyos por hereje.

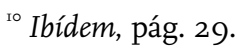


Miguel Servet nació un 29 de septiembre de I5ı en Villanueva de Sijena (Huesca) y desarrolló sus estudios entre en el monasterio del mismo nombre, Montearagón, Zaragoza y puede ser que Barcelona. Por circunstancias de la vida, su padre, notario en dicho pueblo, consigue su incorporación como paje y, luego, secretario del que será confesor del Emperador, fray Juan de Quintana. La influencia de este clérigo oscense, directa o indirectamente, sobre Servet será considerable. Primeramente, porque, gracias a ir en su séquito, pudo conocer las discusiones y la reacción de la Iglesia española ante la Reforma protestante y, en especial, ante su efecto en la religiosidad de la sociedad peninsular. Visitó diferentes ciudades -Valladolid, Toledo y Granada- fue testigo de autos de fe inquisitoriales, conoció las fuentes del erasmismo español y, finalmente, estuvo presente en la coronación del Carlos V como emperador en Bolonia. Mientras, aprovechando un breve período en su trabajo con fray Juan de Quintana, se licenció en Derecho por la Universidad de Toulouse.

Los fastos de la coronación impresionaron tanto al joven oscense que abandonó a fray Quintana para iniciar su particular proyecto de reforma de la Iglesia y, sobre todo, del cristianismo. ¡Hasta tal punto le pareció fatuo y superficial el papel de Papa en su puesto de soberano terrenal! ¡Tan contrario a los objetivos del cristianismo fue el espectáculo organizado por el poder temporal y el poder espiritual! Un triunfo político para el Emperador, pero un error en materia de religión, dado que ya se había producido en las tierras alemanas el golpe de efecto de Lutero y la reforma protestante se propagaba rápidamente por Centroeuropa.

Servet abandona a fray Juan de Quintana para seguir los vientos de una nueva visión del cristianismo. Tenía I9 años cuando en I530 aparece en Basilea en busca de Erasmo, pero éste ya había abandonado la ciudad y moriría al año siguiente. En Basilea, consigue entrar como discípulo del reformador de la ciudad, Juan Ecolampadio, con quien acabaría discutiendo agriamente. En I53I, aparece en Estrasburgo, ciudad, como otras, en plena ebullición religiosa y en la que existía un importante grupo anabaptista. De este período, son sus dos primeras obras: Sobre los errores de la Trinidad (I53I) y Dos diálogos sobre la Trinidad (1532). Ambos son el antecedente de su obra cumbre, la que le llevó a la hoguera en Ginebra un 27 de octubre de I553. Nada más significativo que el título completo: Restitución del Cristianismo (I553). Y el subtítulo es aún más sugerente: Convocatoria a toda la Iglesia apostólica a volver a los orígenes, a restituir íntegro el conocimiento de Dios, de la fe en Cristo, de nuestra justificación, de la regeneración bautismal, de la cena del Señor; restituirnos por fin el reino celestial, a disolver la cautividad de la impía Babilonia, a destruir de todo al Anticristo $y$ a sus secuaces.

Sus conocimientos médicos, jurídicos, científicos, literarios, filológicos, geográficos, astrológicos, bíblicos sólo se entienden en relación con este objetivo que, muy tempranamente, empezó a esbozar y que tantos dolores de cabeza y sufrimientos acabó por acarrearle $^{\text {II }}$. Sólo así se entiende que su descubrimiento de la «circulación menor de la sangre» no se encuentre en sus estudios de medicina, sino en un libro de restitución teológica como es el libro mencionado. En realidad, Servet creía que el alma humana estaba residenciada en la sangre, especie de elán vital, que, al oxigenarse, se purifica y vivifica nuestro espíritu.

S. Zweig califica a Servet de «francotirador a un tiempo en la filosofía, la medicina y la teología, este espíritu fáustico no encaja plenamente en ninguna ciencia, aunque en todas se inmiscuye» ZwEIG, S., Castellio contra Calvino. Conciencia contra violencia, cit., pág. 204. 
Muy pronto, Miguel Servet fue etiquetado de reformista radical y peligroso por sus ideas antitrinitarias y unitaristas. Pensaba que su primera obra, titulada Sobre los errores de la Trinidad (I53I), publicada cuando tenía veinte años, iba a ser bien recibida y que lograría su consagración como teólogo. Pero no fue así. Y ya cuando el año siguiente ve la luz un segundo tratado sobre la misma cuestión, Dos libros de Diálogos sobre la Trinidad (1532), es tal la condena de católicos, españoles y franceses, y de reformistas, luteranos y calvinistas, que inicia un largo período vital de huidas, exilios, engaños y disfraces. El mismo Servet fue dejando huellas falsas, tomó otras identidades, se escondió, en suma, para no ser reconocido y poder llevar a cabo un proyecto de reforma tan radical que no consideró concluido hasta su Restitución del Cristianismo.

Lo cierto es que la publicación de esos dos textos tuvo consecuencias no esperada para su autor. Servet esperaba que sería reconocido como gran teólogo por los reformistas y que podría discutir con ellos de igual a igual sobre las cuestiones arcana de la teología y de la Iglesia. Nada eso. Fue visto como un parvene, como un joven español alocado, defensor de tesis radicales y fuera del dogma. Dado su carácter excitable, este desencuentro le condujo a numerosos conflictos con los representantes de la Reforma en Estrasburgo, en Basilea, y vio así cerradas sus puertas a su persona y a su trabajo intelectual en Alemania.

No le quedaría más remedio que salir para Francia y ocultar su identidad. Y eso hizo cambiándose el nombre y su procedencia. Ahora se llamará Miguel de Villanueva, natural de Tudela, y así se mantendrá hasta el proceso de Ginebra, cuando su vida ya corría un riesgo seguro y no tenía sentido mantener el engaño. Como afirma el estudioso servetiano A. Alcalá, «la vida del nuevo 'Miguel de Villanueva' se forja al tener que camuflar su identidad desde ese momento, prófugo al mismo tiempo de la justicia española y de la francesa, amén de hereje tanto para los católico-romanos como para los protestantes. En tal condición, se camufla como estudiante, a la vez que procura un medio de ganarse la vida» ${ }^{12}$.

No es cuestión de detallar las diferentes vicisitudes de los siguientes años, ya hecho por otra parte ${ }^{\text {13 }}$. Tan solo destacar algunos hitos vitales relevantes para el futuro de este teólogo reformador. Servet, en su etapa francesa, vivió unos años en París, donde estudió Medicina y conoció a Juan Calvino, pero, de naturaleza rebelde, tuvo pronto que salir de la ciudad, a raíz de los hechos ya relatados del discurso inaugural del Rector Nicolás Cop. En este primer momento, Calvino y Servet coinciden en sus vivencias, pero los desencuentros se inician ya y se agrandarán con el tiempo.

De París va a Lyon donde elabora una muy importante edición crítica de la Geografía de Ptolomeo. Aquí conocerá a un personaje muy importante en su vida que le acabará reconduciendo a París y a sus estudios de Medicina. Se trata de Sinforiano Champier, médico, erudito, filósofo neoplatónico, teólogo, abogado y astrónomo. Un hombre de su tiempo.

En 1536 Miguel Servet (o Miguel de Villeneufve o Villanovano) regresa a París iniciando el curso siguiente sus estudios de Medicina. Le precedía su fama por la edición de la Geografía de Ptolomeo, lo que le abrió algunas puertas y le permitió dar alguna

\footnotetext{
${ }^{12}$ AlCAlÁ, A., «Introducción» a SerVEt, M., Obras completas, t. I, Zaragoza, Prensas Universitarias, 2003, pág. LXVII.

${ }^{13}$ Vid. Martínez de Pisón, J., Semblanza de Miguel Servet. Reformador y defensor de la libertad de conciencia, Logroño, Servicio de Publicaciones de la Universidad de La Rioja, 20 I2.
} 
conferencia sobre geografía y astronomía. A la larga, esta afición, como veremos, le acarrearía nuevos problemas con la justicia parisina.

Mientras, desarrolla su formación médica de la mano de «buenos maestros», entre los que destaca el famoso anatomista Juan Guenther de Andernach, quien en el prólogo de su obra Institutiones anatomicae citará entre sus discípulos más allegados a Servet. Además, de la mano de este maestro en anatomía, el aragonés conoció y compartió experiencias médicas con el que sería el anatomista más famoso de la época: con Andrés Vesalio, padre de De humani corporis fabrica. Sin duda, fruto de esta colaboración, de las disecciones y análisis corporales, de conocimiento y de la crítica a Galeno, de su estudio de la medicina arábiga, surgirá la concepción servetiana de la circulación menor de la sangre. Mientras tanto, mostró sus investigaciones, sus aficiones y su práctica médica en un librito de éxito titulado Tratado universal de los jarabes, varias veces editado en vida del autor.

Pero, el inquieto Servet se buscaría nuevos problemas. Además de preparse y formarse en la profesión médica, Servet cultivó otra pasión de Sinforiano Champier, la astronomía, de la que no sólo fue su practicante, sino que, además, por sus conocimientos, fue llamado a impartir interesantes conferencias y lecciones. A estas asistió alguien que sería también decisivo en su vida, el joven obispo Pierre Palmier, quien, con posterioridad, le invitaría a vivir y trabajar en Viena del Delfinado en los años más felices de la no larga existencia de Servet.

Las lecciones de Servet fueron derivando de la astronomía a la «astrología judiciaria», una seudo-ciencia, declarada entonces como herejía, y que sustentaba en la tesis de que existe un nexo determinante entre los fenómenos de universo (macrocosmo) y los fenómenos naturales (microcosmos). Dicho de otra manera, que es posible, a la vista de los alineamientos de los astros, conocer y anticipar hechos que conciernen a la conducta y a la vida los hombres y, por ende, de los gobernantes y de las sociedades. Parece que, incluso, Servet llegó a prever un eclipse de Marte por la Luna para el i3 de febrero de I538. Este se cumplió y la interpretación del astrólogo fue que se produciría una mayor excitación del corazón de los leones, esto es, de los príncipes, y que de ello derivarían guerras y los peores males.

Lo que se inflamó fue el corazón de Servet cuando fue denunciado ante el decano de la Facultad de Medicina y su proceso fue llevado al Parlamento de París que, con todo, dictó el i8 de marzo de 1538 una sentencia leve que aún le permitió seguir sus estudios de medicina. Teniendo en cuenta que ya pudo ser condenado por hereje y condenado por ello a muerte. Pero, el contumaz aragonés respondió con altanero escrito de apología de la astrología judiciaria (Apologetica Disceptio pro Astrologia).

De nuevo, Servet sale de París y tras un tiempo de ciudad en ciudad aparece, invitado por su amigo el obispo P. Palmier, en Viena del Delfinado, pequeña población cercana a Lyon. Como afirma uno de los estudiosos de Servet: «Es opinión aceptada que los doce años que Servet pasó en Viena del Delfinado, en la ribera del Ródano y a la sombra de los Alpes, bajo la protección del arzobispo Palmier, debieron ser los más felices de su atribulada existencia» ${ }^{\mathrm{I} 4}$. Y, en efecto, así parece, pues llevó una vida integrada en la comunidad en la que ejercía de médico como un ciudadano normal. Pero... Al mismo

\footnotetext{
${ }^{14}$ Martínez Laínez, F., Miguel Servet. Historia de un fugitivo, Zaragoza, Institución Fernando el Católico, 20II, pág. 99.
} 
tiempo, iba elaborando y madurando su gran proyecto teológico, la restauración del cristianismo primigenio. Nada más significativo sobre la personalidad y la experiencia vital de Servet que esta doble vida: durante el día, el médico Miguel de Villeneufve o Villanobano, nacido en Tudela; durante la noche, el teólogo Miguel Servet, alias Revés, nacido en Villanueva de Sijena.

Pero, Servet no podía vivir sin resolver las cuestiones teológicas que, desde hacía tiempo, eran el objeto de su polémica con el bando reformista y, en particular, con Calvino. Como ya sabemos, su tesis ya habían sido expuestas, con más o menos claridad, en sus dos obras de I53 y I532, los Sobre los errores de la Trinidad y Dos Diálogos sobre la Trinidad. No obstante, el médico sijenense no estaba del todo satisfecho con su elaboración sistemática. O, quizás, con la repercusión que sus ideas habían tenido en el debate religioso general.

No se tiene constancia de la fecha en la que Servet empieza a reelaborar su pensamiento en el escrito Restitución del Cristianismo, pero sí consta que, cuando ya tenía el manuscrito avanzado, se lo envió a Calvino, según aparece en una relación epistolar que se inicia en $1546^{15}$. Error fatal, pues jel reformador ginebrino utilizará esta correspondencia, primero, para hacer que la Inquisición francesa lo aprese y, segundo, en el propio proceso que se seguirá en la ciudad de Ginebra y que le llevará a la hoguera!

La edición de Restitución del Cristianismo sale de la imprenta en enero de I553. Un total de ochocientos ejemplares, de los que sólo quedan completos dos. A partir de este momento, se suceden vertiginosamente los acontecimientos hasta la quema en la hoguera de Servet, el autor, y de buena parte de su obra, en la colina cercana a Ginebra, conocida con el nombre de Champel o Campo del Verdugo. Era un infausto 27 de octubre de 1553.

La relevancia de Miguel Servet para la historia de la idea de la tolerancia y de la libertad de conciencia no sólo se basa en el injustificado castigo que soportó por su disidencia teológica, por su herejía o porque sus creencias eran diferentes a las de Calvino, quien le condenó, a la postre, a muerte. Sin duda, su gesto, incluso cuando ya las llamas ya empezaban a abrasarle, es digno de mención. Pues, no puede ignorarse que Guillermo Farel, el lugarteniente de Calvino que lo acompañó todo el camino hasta el Campo del Verdugo, fue preguntándole: «¿Crees en Jesucristo, Hijo eterno de Dios?». Si Servet hubiera respondido afirmativa, hubiera salvado su vida. Pero no. Recalcitrante, respondió con la frase que resume su teología radical: «¡Creo en el Cristo verdadero, hijo de Dios, pero no eterno!». Su suerte estaba echada. Los calvinistas y los luteranos, como la Iglesia católica, mantenían el dogma de la Santa Trinidad, en la que el aragonés no creía ${ }^{\mathrm{I}}$.

\footnotetext{
${ }^{15}$ En I546, Servet inicia una relación epistolar y, al mismo tiempo, un breve debate teológico con Calvino a través de persona interpuesta. En efecto, utilizó al editor de la Restitución, Jean Frellon, para enviarle un ejemplar, la que sería utilizada en su contra en el proceso de Ginebra. Quería saber su opinión, pero, sobre todo, demostrar que era un gran teólogo. Puede verse la relación epistolar en SERVET, M., Obras completas, cit., vol. I págs. 44-52. Asimismo, puede verse en el mismo volumen la interesante reconstrucción de Ángel Alcalá de esta relación epistolar Calvino-Servet, así como la reacción del primero y su carta a G. Farel en la que habla de los delirios teológicos del aragonés y del envío del manuscrito citado. Todo ello perfectamente documentado. AlCAlÁ, A., «Introducción» a SERVET, M., Obras completas, cit., pág. CXVII.

${ }^{16}$ Existen varias referencias escritas al momento final de la muerte de Servet en la hoguera en ese fatídico día de octubre de I553. Una de ellas del mismo Guillermo Farel que lo acompañó hasta el montón de leños donde iba a arder. Además, ha sido recreado poéticamente no pocas veces. Algunos documentos de la época han sido recogidos en SERVET, M., Obras completas, cit., vol. I, págs. 254-260.
} 
En varios momentos de su corta vida y de su obra, Servet reivindicó la libertad de conciencie, de «su» conciencia. Cuanto más se acerca el momento final, lógicamente, alzará su voz con más insistencia. Esta llamada angustiosa y trágica acabará impulsando la reacción de Castellio y de otros contra Calvino, su sentencia y a favor de la libertad de conciencia. Como afirma Ángel Alcalá, «resulta de importancia trascendental en la historia de las ideas comprobar que Servet es el primer pensador cristiano que al cabo de centenares de años proclama este principio trascendental» ${ }^{\text {r7 }}$.

La primera referencia servetiana a la libertad de conciencia la realiza prontamente. Aparece, según ha investigado Ángel Alcalá, en su relación epistolar con Juan Ecolampadio, reformador de Basilea que, primero, fue maestro de Servet, pero que, al final, acabó echando a un discípulo discutidor y díscolo. Este aclara su posición así a su maestro:

\begin{abstract}
«Dios sabe que mi conciencia ha sido limpia en todo lo que he escrito, aunque tú quizá pienses lo contrario por mis crudas palabras. Si en tu espíritu hay miedo, tinieblas o confusión, no podrás juzgar el mío con claridad, y, aunque me sepas equivocado en algo, no por eso me debes condenar en todo lo demás. Si así fuera, no habría mortal que no debiera ser mil veces quemado. Propia de la condición humana es esta enfermedad de creer a los demás impostores e impíos, no a nosotros mismos, porque nadie reconoce sus propios errores. Me parece grave matar a un hombre solo porque en alguna cuestión de interpretar la Escritura esté en error, sabiendo que también los más doctos caen en él. Y bien sabes tú que yo no defiendo mis ideas tan irracionalmente que se me haya de rechazar así»».
\end{abstract}

Durante el irregular proceso vivido en Ginebra, pues se realizó sin las debidas garantías para el reo, incumpliendo las normas de la propia ciudad y en condiciones inhumanas e indignas, Servet volvió a repetir esta tesis en defensa de su posición y de su conciencia. El 22 de agosto de I553, cuando ya se había producido un primer interrogatorio, Servet dirige una carta al Consejo de Ginebra. En ella, desmonta la idea de que debe ser acusado ante la autoridad criminal por el hecho de interpretar las Sagradas Escrituras sin haber cometido ningún delito de acuerdo con las leyes de la ciudad y que debiera remitirse la causa a la autoridad religiosa, pues las cuestiones que se dirimen son cuestiones teológicas que sólo a las Iglesias interesan. Que, aún más, los teólogos tienen que decidir y que, en definitiva, su planteamiento no tiene consecuencias para la vida social. Servet retoma la antigua política del cristianismo anterior al siglo IV cuando les espeta a los miembros del Consejo: «Todas las cuestiones serían decididas por las iglesias y el que fuera convicto o condenado por ellas, si no quiere arrepentirse, sería excluido. Ese castigo fue siempre observado en la primera Iglesia contra los herejes...».

Esta tesis está en consonancia con su proyecto principal de restitución del cristianismo en la versión de las primeras comunidades y de sus prácticas anteriores al Concilio de Nicea. En esta misma línea, les recuerda que «por haber destacado ciertos puntos de los antiguos doctores de la Iglesia, sin ningún ánimo de sedición, no debe en modo alguno estar detenido y sometido a una acusación criminal» ${ }^{\text {I9 }}$. Es el escrito en el que describe las paupérrimas condiciones en las que vive preso, así como pone de manifiesto su

\footnotetext{
${ }^{17}$ AlCALÁ, A., «Introducción» a Miguel Servet Obras completas, cit., pág. CXVIII.

${ }^{18}$ Ibídem, pág. CXIX.

${ }^{19}$ Servet, M., Obras completas, edición de Alcalá, A., t. I, Zaragoza, Prensas Universitarias, 2003, págs. I3II32.
} 
condición de extranjero, su desconocimiento de las leyes del país y, en consecuencia, la necesidad de nombrarle un defensor. Aunque se aprobaron mejoras en las condiciones materiales de vida en la cárcel, estas órdenes no se cumplieron y careció en todo momento de abogado que defendiera su causa.

En suma, esta reivindicación de la Iglesia de los primeros tiempos, de sus normas y de sus prácticas, era una denuncia de la intolerancia y de los métodos represores impuestos a partir de Constantino. En cuanto a sus defensores, éstos sólo los encontraría ya muerto y fueron muchos a partir de la lucha iniciada por Castellio.

Los mismos argumentos volverán a ser esgrimidos por Servet ya directamente contra Calvino en su escrito de 22 de septiembre de 1553 cuando su final se acercaba ya. En el punto 6 del mismo vuelve a la carga preguntándole «si no sabe perfectamente que no es oficio de un ministro del Evangelio transformarse en acusador criminal, ni perseguir judicialmente a muerte a nadie». Y, con toda su osadía, contraataca acusando a Calvino de abusar, siendo ministro del Evangelio, de la criminalidad en cuestiones religiosas, de ser un «falso acusador», de «ahogar la verdad de Jesucristo» con «frívolas y calumniosas razones», y de introducir «grandes mentiras y maldades», y, finalmente, de seguir la doctrina de Simón el Mago, por lo que debe ser condenado, «exterminado y expulsado de vuestra ciudad» y sus bienes entregados a la persona de Servet ${ }^{20}$.

Según el especialista servetiano, A. Alcalá, de estos textos, «se deduce que la defensa de la libertad de conciencia por Servet formó parte tan decisiva de su doctrina desde sus primeros escritos juveniles $\mathrm{y}$, en consecuencia, parte integrante de su fatal proceso ginebrino, como las 'herejías' por las que fue condenado, una de las cuales, según Calvino, era esa misma defensa de la libertad» ${ }^{21}$.

Servet, en resumidas cuentas, además de discutir las cuestiones teológicas que había desarrollado en sus escritos, principalmente en Restitución del Cristianismo, utiliza en su defensa un argumento olvidado prácticamente desde los primeros tiempos de la Iglesia: que los jueces civiles y criminales no pueden juzgar y condenar a los herejes. Tal será la idea y el legado que, tras su muerte, se extenderá en determinados círculos -en Basilea, en Polonia, en Holanda- y que será uno de los pilares de la reivindicación de Sebastián Castellio de su figura poco tiempo después, iniciándose así la historia de la lucha por la tolerancia y por la libertad de pensamiento y de conciencia ${ }^{22}$.

\section{Sebastián Castellio, infortunado defensor de la tolerancia y humanista.}

Una de las páginas más brillantes de la historia de la libertad de conciencia y, por tanto, de los derechos fundamentales será escrita a partir de la muerte de Servet en la hoguera condenado por hereje. No fue el primero ni el último de los declarados herejes que pagó con su vida su disidencia teológica. Pero la muerte de Servet, que no era objeto de las simpatías ni de unos ni de otros, causó tanto horror que lentamente se inició un movimiento de reivindicación de la tolerancia y de la figura del médico, teólogo y

\footnotetext{
${ }^{20}$ Ibídem, págs. 243-244.

${ }^{21}$ SERVET, M., Obras completas, cit., p. CXX.

${ }^{22}$ Vid. MARTínez DE PISÓN, J., Tolerancia y derechos fundamentales en las sociedades multiculturales, Madrid, Tecnos, 200I.
} 
astrónomo aragonés. Este proceso empezará a partir de las iniciativas de Sebastián Castellio e implicará a otros filósofos e intelectuales entre los que destaca ya posteriormente a Voltaire.

El mismo Calvino no debería tener la conciencia muy tranquila pues tuvo que salir en su propia defensa analizando el proceso y la condena de Servet en su Defensio orthodoxae fides $^{23}$ (I554) en la que el reformador -iparadojas de la historia!- rechaza la libertad de conciencia y justifica la condena a muerte de los herejes. Años antes, en el inicio del movimiento reformador, Calvino adujo la libertad de conciencia para defender su derecho a interpretar las Sagradas Escrituras de forma diferente a la Iglesia de Roma. Ahora, como buena parte de los reformadores, negará tal libertad para las sectas que surgían al albur del proceso de Reforma de la religión. Y anabaptistas, socinianos, unitarios y demás sufrieron la represión teológica en sus bienes y personas.

Sebastián Castellio nació en 1515 en un pueblo cercano a Lyon, llamado SaintMartin-du-Fresne, que distaba, a su vez, a uno $70 \mathrm{~km}$ de la ciudad de Ginebra. Aunque de familia de campesinos, sin embargo, Castellio pudo realizar estudios clásicos, latín y griego e, incluso, hebreo. Su formación, sobre todo, fue filológica y la adquirió en el Colegio Trinidad de Lyon, fundado por el que será amigo de Servet, Sinforiano Champier. Aunque, con el tiempo, sus inquietudes se orientarán hacia la teología y, en particular, hacia los temas clave de la Reforma, su mentalidad era claramente una mentalidad de filólogo. Y así se notará en el interés, en el tiempo y en el esfuerzo que dedicará al estudio de la Biblia y a su traducción al francés. Para algunos, ya sólo la culminación de esta gran empresa, la traducción al francés de la Biblia, ya la garantiza un puesto importante en el Olimpo de las letras.

Los aires de la Reforma impregnaron la vida en la industriosa Lyon y la crisis religiosa no dejó impertérrito a nadie. En este contexto, Castellio, de espíritu inquieto y preocupado por el debate religioso recién iniciado, se dejó seducir por la lectura de Calvino y su Instituciones de la Religión Cristiana. Por otra parte, el ambiente religioso en la ciudad de Lyon se fue, poco a poco, haciendo insoportable, una vez que la Inquisición francesa empezó a perseguir a los protestantes y a castigarlos a la hoguera por herejes. De ahí que Castellio abandonase Lyon en I540 en dirección a Estrasburgo con el objetivo de conocer a Calvino quien, en ese momento, había buscado refugio en esa ciudad tras su marcha forzada de Ginebra (1538-I54I). La Iglesia reformada de Estrasburgo estaba dirigida por Juan Ecolampadio y, por esa ciudad, ya había pasado años antes Servet siguiendo los pasos de Erasmo, habiendo sido discípulo del maestro reformador.

En Estrasburgo, Castellio conoció a Calvino y a Guillermo Farel, el estrecho colaborador del reformador ginebrino. E, incluso, se hospedó en la casa del primero. De esta manera, Castellio se convirtió en uno más de la causa reformista inspirada por Calvino. De hecho, acompañó a éste en el regreso a Ginebra en I54I y, por tanto, en la etapa de más avance reformador en esta ciudad. Al principio, por tanto, Castellio fue uno más de los calvinistas que debían construir la utopía teológica en la tierra suiza. De hecho, no sólo fue en el séquito de Calvino en su vuelta triunfal, sino que, pronto, fue propuesto por Farel, con

\footnotetext{
${ }^{23}$ El texto completo del título es Defensio orthodoxae fidei de sacra Trinitate contra prodigiosos errores Michaelis Serveti Hispani (Defensa de la fe ortodoxa sobre la sagrada Trinidad, contra los prodigiosos errores del español Miguel Servet).
} 
la aquiescencia del primero, para dirigir el influyente Collège de Rive que pretendía ser la institución educativa por excelencia de formación de las elites calvinistas. Además fue nombrado predicador en un pueblecito cerca de Ginebra, en Vandoeuvres.

Sin embargo, el nombramiento, según se supo por voluntad de Calvino, era provisional a la espera de designar a alguien con más prestigio internacional que Castellio, pues el proyecto era crear una institución de nivel superior. Pero, el elegido para el cargo no aceptó la propuesta de Calvino por lo que Castellio fue confirmado en el cargo.

Los biógrafos de uno y otro señalan que pronto surgieron las desavenencias entre ambos teólogos. El primer conflicto serio tuvo lugar a raíz del proyecto de Castellio de publicar una traducción al francés del Nuevo Testamento. No olvidemos que, por formación, era filólogo y aplicó sus conocimientos a esta tarea de traducir las Sagradas Escrituras al francés. Su idea era publicarlo en Ginebra y, para ello, necesitaba el placet del reformador, quien, sin embargo, hizo numerosas anotaciones y correcciones a la traducción de Castellio. Este se negó a aceptarlas ante lo cual decidió abandonar el proyecto. Mientras, fue elaborando unos Dialogi sacri, una especie de manual dialogado de enseñanza del Antiguo y del Nuevo Testamento. Con esta obrita, Castellio logró un merecido éxito hasta el punto de que no sólo tuvo numerosas ediciones, sino que fue ampliamente utilizado para la enseñanza bíblica y del latín.

La tensión entre Calvino y Castellio fue creciendo e, incluso, se hizo pública con motivo de una peste que asoló la ciudad entre I542 y i543. Castellio puso en evidencia la falta de coherencia entre lo que predicaban Calvino y los suyos y lo que luego practicaban, pues dejaron sin los cuidados y sin el consuelo espiritual a quienes enfermaron de la peste. A pesar de que solicitó acudir al hospital para cumplir con lo que consideraban su deber, no se le concedió. Fueron años duros para la ciudad de Ginebra y, para algunos, los predicadores calvinistas se despreocuparon del dolor de los ciudadanos. Incluso, en los años posteriores, se extendió una hambruna importante entre los límites de la urbe, lo que exigió medidas excepcionales de ayuda y cuidado. Pero las desavenencias entre ambos eran ya una realidad.

Castellio presentó la renuncia a la dirección del Collège de Rive que, en un principio, no fue admitida. Además, solicitó que fuese nombrado pastor de Ginebra, en lugar de continuar en Vandeoubres. A pesar de que el Consejo de la ciudad aceptó su petición, sin embargo, Calvino puso una serie de pegas teológicas de carácter menor que impidieron, finalmente, su nombramiento. Finalmente, Castellio reprochó públicamente a los predicadores calvinistas su comportamiento bajo la peste en las Congregaciones de los ministros ginebrinos, Tras ello, el Consejo suspendió el I2 de junio de I544 a Castellio de sus funciones pastorales en Vandeoubres y, poco después, aceptó su renuncia a la dirección del Collège de Rive. A la vista de la situación, Castellio decide abandonar Ginebra.

Castellio tuvo serias dificultades en encontrar trabajo, pues la larga mano de Calvino hizo todo lo imposible por impedir su estabilidad laboral y económica y la de su familia. Fueron tiempos duros y lo seguirían siendo; mucho trabajo para malvivir, para mantener una numerosa familia, pero Castellio lo llevó con resignación y paciencia.

Finalmente, Castellio consiguió un puesto de corrector en una imprenta de Basilea. Ahí, alternó este trabajo con todos los empleos que pudo lograr con el fin de mantener a su familia. Sus condiciones económicas siguieron siendo muy precarias hasta que obtuvo un 
puesto de profesor en la Universidad de Basilea. Aquí pudo desarrollar su carrera académica llegando a obtener el grado de magister artium.

Es en esta etapa en la que Castellio desarrolla sus proyectos intelectuales de más envergadura. En particular, su gran proyecto de traducir la Biblia al latín (I55I) y, sobre todo, al francés (I555). Consideraba que las traducciones al uso contenían muchos errores y, además, no se puede olvidar que la elaboración de versiones de la Biblia en las lenguas vernáculas era uno de los proyectos centrales de los reformadores. Las traducciones de Castellio no pasaron desapercibidas, siendo criticadas por muchos teólogos, incluido Calvino. El autor aplicó su formación filológica y sus conocimientos de hebreo, del latín y del griego para elaborar una versión que en algunos puntos importantes no coincidía con las ediciones oficiales.

Sin embargo, lo que le va a traer más fama y muchos quebraderos de cabeza va a ser su intervención en el debate sobre el trato que hay que dar a los herejes y, en particular, la crítica a Calvino por la condena al hereje Servet. Sus reflexiones no sólo tendrán por objeto negar la validez de las persecuciones del disidente, sino también el de justificar la tolerancia religiosa.

Como ya sabemos, Miguel Servet fue condenado y quemado en la hoguera por hereje un 27 de octubre de 1553 en Champel, la colina del Verdugo, en Ginebra. Un justificada indignación se extendió entre un sector importante de la intelectualidad europea que vieron con horror el impropio proceso y la injustificada condena del sabio aragonés por mucho que sus ideas no fueran bien vistas por casi nadie, salvo anabaptistas, unitarios y socinianos. El mismo Calvino salió en su propia defensa, justificando su conducta y la sentencia final, en su libro Defensio orthodoxae fides. En este escrito, Calvino justifica el uso del poder civil y de la magistratura para perseguir, castigar y condenar a los herejes.

Pero, lo que era un murmullo, esto es, la desaprobación por la muerte de Servet, fue poco a poco saliendo a la luz por mucho que Calvino y los suyos quisieran meterle sordina a la crítica cada vez más evidente. Fue finalmente Castellio quien salió de la sombra y del despacho de filólogo y, jugándose su prestigio y su vida, puso las cosas claras al afirmar que, después de todo, quemar a un hereje no dejar de ser un asesinato, esto es, matar a un hombre. Es conocida la frase aparecida en su libro Contra el libelo de Calvino: «Matar a un hombre no es defender a una doctrina, es matar a un hombre. Cuando los ginebrinos mataron a Servet, no defendieron una doctrina, mataron a un hombre. Defender la doctrina no es propio del magistrado (¿qué tiene que ver la espada con la doctrina?), sino del doctor» ${ }^{24}$.

Pero, la primera respuesta a la decisión de los calvinistas y al libro de Calvino fue la aparición de un texto con seudónimo y un título muy significativo: Sobre si los herejes deben ser perseguidos. A pesar de ir firmado con el nombre de Martinus Bellium, los estudiosos atribuyen la paternidad de esta obra a Castellio ${ }^{25}$. El libro recogía una serie de textos de diversos autores y teólogos con opiniones contrarias a la aplicación de la pena de muerte a los herejes. Entre ellas, alguna del mismo Calvino. Parece, no obstante, que su elaboración

${ }^{24}$ Castellio, S., Contra el libelo de Calvino, trad. y notas de J. Fernández Cacho, revisión de A. Gómez, Huesca, Instituto de Estudios Sijenenses Miguel Servet, 2009, pág. I07.

${ }^{25}$ Ibídem, pág. I7. 
se realizó unos meses antes de la condena de Servet, aunque viese la luz con posterioridad coincidiendo con la publicación del texto de defensa de Calvino.

Donde no hay duda de la paternidad e intención del autor, es decir, de Castellio, fue en el mencionado libro Contra el libelo de Calvino (I554). Aparecido el mismo año que el texto de Calvino, el autor toma cada una de sus ideas desmenuzándolas con ironía y sarcasmo y, a veces, hasta con un exceso de violencia. Pero, la idea central es muy clara: que en las Sagradas Escrituras no se encuentra fundamento para la pena de muerte para los herejes. En efecto, Contra el libelo de Calvino es un texto se basa en la tesis de la carencia de justificación bíblica para el castigo que sufrían los herejes. Desde un principio, aclara el autor que no entra a valorar, ni apoyar las ideas de Servet, sino que su objetivo es refutar el proyecto reformador, el de Calvino, que utiliza a los magistrados y que castiga duramente a los disidentes.

El texto de Castellio es un texto vibrante, realizado con ánimo de polemizar y de ridiculizar al todopoderoso reformador de Ginebra. Por ello, abundan expresiones duras, mucha retórica y algo de pasión, lo que explica alguno de sus excesos. Véase un ejemplo: «(Calvino) quiere matar a todos los herejes y quiere que todos los que disienten de él sean considerados herejes. De ahí que todos los papistas, luteranos, seguidores de Zwinglio, anabaptistas y cualesquiera otros, si los hay, deban ser, de acuerdo con el parecer de Calvino, condenados a muerte y que sobrevivan en la tierra únicamente los calvinistas junto a los turcos y los judíos, con quienes hace una excepción» ${ }^{26}$.

Calvino no puede encontrar ningún texto en los Evangelios, ni existe una autoridad sólida que justifique la tesis de que los jueces cristianos pueden castigar a los herejes, «y lo único que hace sostener lo que sostiene es su deseo de dominar, su sed inextinguible de sangre» ${ }^{27}$.

Calvino hizo todo lo posible para que el texto de Castellio no encontrase un editor e, incluso, lo acabó acusando de hereje antes las autoridades de Basilea. No obstante, el texto fue transcrito en diversos manuscritos que pasaron de mano en mano teniendo así una amplia difusión. Como afirma un estudioso de la obra de Servet y de la implicación de Castellio, «pese a no ser un 'best seller', la obra de Castellio no pasó desapercibida y se erigió con el tiempo en uno de los más clarividentes alegatos en favor de la libertad de conciencia. Por lo tanto, sería difícil reconstruir los orígenes de la idea occidental de libertad religiosa sin remitirse a esta obra $»^{28}$.

\section{V.Bibliografía}

AlCALÁ, A, «Los dos grandes legados de Servet: el radicalismo como método intelectual y el derecho a la libertad de conciencia», Turia. Revista cultural, 63-64, 2003, págs. 221-242.

— «Nuestra deuda con Servet: inspiraciones de su doctrina para el siglo XXI», en BACHES, S. (coord.), Miguel Servet, luz entre tinieblas, Huesca, Instituto de Estudios Sijenenses Miguel Servet, 2006, págs. 25-43.

\footnotetext{
${ }^{26}$ Ibídem, págs. 65-66.

${ }^{27}$ Ibídem, pág. 66.

${ }^{28}$ BACHeS, S., «Introducción a la vida y obra de Sebastián Castellio» en CASTELLIO, S. (2009), Contra el libelo de Calvino, cit., pág. 20.
} 
— «La sinrazón de la intolerancia en Tomás de Aquino y Juan Calvino: su rechazo por Miguel Servet, origen de la libertad de conciencia», en ESCUDERO, J.A. (coord.), Intolerancia $e$ Inquisición, Madrid, Sociedad Estatal de Conmemoraciones Culturales, 2006, págs. 83-I07.

BADA, J., La tolerancia entre el fanatismo y la indiferencia, Estella-Navarra, Verbo Divino, I996.

BETES, L., «El pensamiento teológico de Miguel Servet», Turia. Revista cultural, 63-64, 2003, págs. $255-264$.

BaCHes, S. (coord.), Miguel Servet, luz entre tinieblas, Huesca, Instituto de Estudios Sijenenses Miguel Servet, 2006.

— «Miguel Servet: apuntes sobre su vida, obra y legado», en BACHES, S. (coord.), Miguel Servet, luz entre tinieblas, Huesca, Instituto de Estudios Sijenenses Miguel Servet, 2006, págs. 26I-278.

BaChes, S. y Gómez, A. (ed.), Miguel Servet, eterna libertad. V Centenario de su nacimiento (1511-2011), Huesca, Instituto de Estudios Sijenenses Miguel Servet, 2012.

Bodin, J., Los seis libros de la República, selecc., trad. y estudio preliminar de P. Bravo, Madrid, Tecnos, I985.

CAlvino, J., Institución de la religión cristiana, 2 vol., trad. de C. de Valera, reedit. por L. de Usoz, Madrid, Visor, 2003.

CASTEllio, S., Contra el libelo de Calvino, trad. y notas. de J. Fernández, revisión y notas de A. Gómez, Huesca, Instituto de Estudios Sijenenses Miguel Servet, 2009.

CASTELlOTE, S., Reformas y Contrarreformas en la Europa del siglo XVI, Madrid, Akal, I997.

CotTret, B., Calvino. La fuerza y la fragilidad. Biografía, trad. de $\mathrm{M}^{\mathrm{a}} \mathrm{T}$, Garín, Madrid, Editorial Complutense, 2002.

Crouzet, D., Calvino, trad. I. Hierro, Barcelona, Ariel, 2oor.

FERRER BENIMELI, J. A., «Calvino y Servet: otra forma de Inquisición», en EsCUdERO, J.A. (coord..), Intolerancia e Inquisición, Madrid, Sociedad Estatal de Conmemoraciones Culturales, 2006, págs. 59-8I.

FETSCHER, I., La tolerancia: una pequeña virtud imprescindible para la democracia, trad. de N. Machain, Barcelona, Gedisa, I994.

GARZÓn VAldÉs, E., Derecho, ética Y política, Madrid, Centro de Estudios Constitucionales, I993.

Gómez RabAl, A., «Vida de Miguel Servet», Turia. Revista cultural, 63-64, 2003, pág. 209.

HiLlar, M., «El legado de Servet. El camino del reconocimiento de la libertad de conciencia como derecho natural y cambio de paradigma social: de Servet a Thomas Jefferson», en BACHES, S. (coord.), Miguel Servet, luz entre tinieblas, Huesca, Instituto de Estudios Sijenenses, 2006, págs. 93-108.

- «La Christianismi Restitutio (Restitución del Cristianismo): el programa religioso de Miguel Servet», en BACHES, S. (coord.), Miguel Servet, luz entre tinieblas, Huesca, Instituto de Estudios Sijenenses, 2006, págs.45-68.

KAMEN, H., Nacimiento $y$ desarrollo de la tolerancia en la Europa moderna, trad. de $\mathrm{M}^{\mathrm{a}}$ J. del Río, Madrid, Alianza, I987.

LECLERC, J., Historia de la tolerancia en el siglo de la Reforma, versión española de A. Molina, 2 vols, Alcoy, Marfil, ig69.

Locke, J., Carta sobre la Tolerancia, edic. de P. Bravo, Madrid, Tecnos, I985.

LuCAS, J. DE, «Para dejar de hablar de la tolerancia», Doxa, Cuadernos de Filosofía del Derecho, II, I992, págs. II7-I26.

MARTínEZ DE Pisón, J., Tolerancia $y$ derechos fundamentales en las sociedades multiculturales, Madrid, Tecnos, 200I.

— «Tolerancia y derechos en las sociedades multiculturales», en TORRES AGUILAR, M. y SALAZAR, O. (edit.), La inclusión del otro: más allá de la tolerancia, Córdoba, Universidad de Córdoba, 2007, págs. I59-194. 
- Semblanza de Miguel Servet. Reformador y defensor de la libertad de conciencia, Logroño, Universidad de La Rioja, 2012.

— «El tortuoso camino hacia la libertad de conciencia: Miguel Servet y José $\mathrm{M}^{\mathrm{a}}$ Blanco White», en BACHes, S. y Gómez, A. (eds.), Miguel Servet, eterna libertad, Huesca, Instituto de Estudios Sijenenses Miguel Servet, 2012, págs. I53-182.

— «De la tolerancia religiosa a la libertad de conciencia. Un viaje inconcluso (s. XVI-XXI)», Melanges de la Casa de Velázquez, 44, 20I4, págs. II-I30.

Martínez de Pisón J., y Aguirre, J. M. (coords.), Pluralismo $y$ tolerancia: la sociedad liberal en la encrucijada, Logroño, Perla, 2004.

Martínez Laínez, F., Miguel Servet. Historia de un fugitivo, Institución Fernando el Católico, Zaragoza, 20II.

Mendus, S. (ed.), Justifying Toleration, Conceptual and Historical Perspectives, Nueva York, Cambridge University Press, I988.

— Toleration and the Limits of Liberalism, Londres, Macmillan, I988.

PÁramo, J. R., Tolerancia y liberalismo, Madrid, Centro de Estudios Constitucionales, I993.

PeCes Barba, G. y FernándeZ, E. (dirs.), Historia de los derechos fundamentales, t. 1., Tránsito a la modernidad. Siglos XVI Y XVII, Madrid, Dykinson/Instituto Bartolomé de Las Casas, I988.

Rivera GARCÍA, A., «El pensamiento jurídico-político de Calvino y el moderno estado de derecho», en SuÁrez Villegas, J. C. (ed.), Reforma protestante y libertades en Europa, Madrid, Dykinson, 2010, págs. 197-228.

SÁrz VAldivieso, A. C., «Fanatismo e intolerancia contra la libertad de pensar (el caso de Miguel Servet)», en Echano, J. I. (coord.), Estudios jurídicos en memoria de José María Lidón, Bilbao, Universidad de Deusto, 2002, págs. I245-I258.

SARTORELli, E. C., «Servet, pensador radical», Turia. Revista cultural, 63-64, 2003, págs. 243-254.

Servet, M., Obras completas, edición de A. Alcalá, 6 vol., Zaragoza, Prensas Universitarias, 2003.

SuÁReZ VillegAS, J. C. (ed.,) Reforma protestante Y libertades en Europa, Madrid, Dykinson, 2010.

Thiebaut, C., De la tolerancia, Madrid, Visor, I999.

VolTAire, Tratado de la tolerancia, ed., prol. y notas de P. Togliatti, Barcelona, Grijalbo, I977.

- Diccionario filosófico, $2^{\mathrm{a}}$ edic., ed. y prólogo de L. Martínez Drake, trad. de J. Areán Fernández y L. Martínez Drake, Madrid, Akal, I980.

ZWEIG, S., Castellio contra Calvino. Conciencia contra violencia, trad. de B. Vías, Barcelona Acantilado, 200 I. 